\title{
LONG-TERM RESULTS OF MITRAL VALVE REPAIR FOR MYXOMATOUS DISEASE WITH AND WITHOUT CHORDAL REPLACEMENT WITH EXPANDED POLYTETRAFLUOROETHYLENE SUTURES
}

Tirone E. David, MD

Ahmad Omran, MD

Susan Armstrong, MSc

Zhao Sun, PhD

Joan Ivanov, MSc
Objective: This study was carried out to evaluate the long-term results of mitral valve repair for mitral regurgitation caused by myxomatous disease of the mitral valve and the late effects of chordal replacement with expanded polytetrafluoroethylene sutures in this operation. Methods: A total of 324 patients with mitral regurgitation caused by myxomatous disease underwent mitral valve repair from 1981 to 1995 ; the group comprised 241 men and 83 women whose mean age was $58 \pm 14$ years. Chordal replacement with expanded polytetrafluoroethylene sutures has been performed in 165 patients since 1985 . Most of the patients who had chordal replacement with expanded polytetrafluoroethylene sutures had prolapse of the anterior leaflet or prolapse of both leaflets, whereas most patients who had mitral valve repair without chordal replacement had prolapse of the posterior leaflet. Patients were followed up at annual intervals and had a Doppler echocardiographic study. The follow-up was complete and extended from 6 to 156 months (mean $36 \pm 30$ months). Results: Two operative and 21 late deaths occurred (14 cardiac and 7 noncardiac). At 10 years the actuarial survival was $75 \% \pm 5 \%$, the freedom from stroke was $94 \% \pm 2 \%$, the freedom from transient ischemic attacks was $92 \% \pm 4 \%$, the freedom from endocarditis was $99 \% \pm 1 \%$, the freedom from mitral valve reoperation was $96 \% \pm 1 \%$, and the freedom from severe mitral regurgitation was $93 \% \pm 3 \%$. Chordal replacement with expanded polytetrafluoroethylene sutures had no effect on any of these end points. Conclusions: Mitral valve repair was feasible in most patients with mitral regurgitation caused by myxomatous disease and it was associated with low rates of valve-related complications. Chordal replacement with expanded polytetrafluoroethylene had no adverse effect on the late outcome and was believed to have increased the probability of mitral valve repair. ( $J$ Thorac Cardiovasc Surg 1998;115:1279-86)
$\mathrm{M}$ yxomatous disease of the mitral valve $(\mathrm{MV})$ is common. It was found in $2.5 \%$ of men and $7.6 \%$ of women in a clinical epidemiologic study by

From the Divisions of Cardiovascular Surgery and Cardiology of The Toronto Hospital and the University of Toronto, Toronto, Ontario, Canada.

Read at the Seventy-seventh Annual Meeting of The American Association for Thoracic Surgery, Washington, D.C., May 4-7, 1997.

Received for publication May 12, 1997; revisions requested August 22, 1997; revisions received Feb. 13, 1998; accepted for publication Feb. 13, 1998.

Address for reprints: T. E. David, MD, 200 Elizabeth St., 13EN219, Toronto, Ontario, Canada M5G 2C4.

Copyright (C) 1998 by Mosby, Inc.

$0022-5223 / 98 \$ 5.00+0 \quad \mathbf{1 2 / 6 / 8 9 6 6 6}$
M-mode echocardiography. ${ }^{1}$ In most patients with myxomatous MV disease, mitral regurgitation (MR) of clinical importance never develops, ${ }^{1,2}$ but because of the high prevalence of myxomatous disease in North America, it is the most common cause of MR that eventually necessitates surgical treatment. ${ }^{3}$ Although myxomatous disease of the MV is more prevalent in women than in men by a ratio of approximately $3: 1, \mathrm{MR}$ is more common in men than in women by a ratio of almost 4:1., 4-6

MV repair has emerged as the procedure of choice for patients with symptomatic MR resulting from myxomatous disease because of its low operative mortality rate and beneficial effects in left ventricular function when compared with mitral valve replacement (MVR). ${ }^{7,8}$ The results of MV 
Table I. Clinical data of patients who had MV repair

\begin{tabular}{|c|c|c|c|c|}
\hline & All patients & ePTFE & No ePTFE & $p$ Value \\
\hline No. of patients & 324 & 165 & 159 & \\
\hline \multicolumn{5}{|l|}{ Age $(y r)$} \\
\hline Mean \pm SD & $58 \pm 14$ & $56 \pm 14$ & $61 \pm 12$ & 0.003 \\
\hline Range & 18 to 88 & 20 to 88 & 18 to 80 & \\
\hline \multicolumn{5}{|l|}{ Sex } \\
\hline Male & $241(74)$ & $130(79)$ & $111(70)$ & \\
\hline Female & $83(26)$ & $35(21)$ & $48(30)$ & 0.064 \\
\hline \multicolumn{5}{|l|}{ Heart rhythm } \\
\hline Sinus & $214(66)$ & $110(67)$ & 107 (67) & \\
\hline Atrial fibrillation & $107(33)$ & $54(33)$ & $50(32)$ & 0.826 \\
\hline Complete heart block & $3(1)$ & 1 & $2(1)$ & \\
\hline \multicolumn{5}{|l|}{ NYHA functional class } \\
\hline I & $26(8)$ & $14(8)$ & $12(8)$ & \\
\hline II & $88(27)$ & $49(30)$ & $39(24)$ & \\
\hline III & $146(45)$ & $75(45)$ & $71(45)$ & \\
\hline IV & $64(20)$ & $27(16)$ & $37(23)$ & 0.415 \\
\hline \multicolumn{5}{|l|}{ Infective endocarditis } \\
\hline Active & $5(1.5)$ & $2(1)$ & $3(2)$ & \\
\hline Healed & $28(9)$ & $20(12)$ & $8(5)$ & 0.07 \\
\hline \multicolumn{5}{|l|}{ Previous cardiac surgery } \\
\hline Mitral valve repair & $5(1.5)$ & $4(2)$ & 1 & \\
\hline Other & $7(2)$ & $5(3)$ & $2(1)$ & 0.273 \\
\hline \multicolumn{5}{|c|}{ Left ventricular ejection fraction } \\
\hline$>55 \%$ & $125(40)$ & $65(39)$ & $64(40)$ & \\
\hline $41 \%-55 \%$ & $170(52)$ & $85(52)$ & $85(53)$ & \\
\hline $21 \%-40 \%$ & $23(7)$ & $13(8)$ & $10(6)$ & \\
\hline$<21 \%$ & $2(0.6)$ & $2(1)$ & 0 & 0.515 \\
\hline \multicolumn{5}{|l|}{ MV disease } \\
\hline Leaflet prolapse & & & & 0.001 \\
\hline Anterior & $58(18)$ & $49(29)$ & $9(6)$ & \\
\hline Posterior & $168(52)$ & $29(17)$ & $139(87)$ & \\
\hline Anterior and posterior & $98(30)$ & $87(53)$ & $11(7)$ & 0.001 \\
\hline \multicolumn{5}{|c|}{ Degree of myxomatous changes } \\
\hline Mild & $175(54)$ & $66(40)$ & $109(68)$ & \\
\hline Moderate & $91(28)$ & $56(34)$ & $36(23)$ & \\
\hline Advanced & $57(18)$ & $43(26)$ & $14(9)$ & \\
\hline Aortic valve disease & $21(6)$ & $17(10)$ & $4(2)$ & 0.004 \\
\hline Tricuspid valve disease & $9(3)$ & $6(4)$ & $3(2)$ & 0.338 \\
\hline Ascending aortic aneurysm & $7(2)$ & $5(3)$ & $2(1)$ & 0.232 \\
\hline Coronary artery disease & $40(12)$ & $16(10)$ & $24(15)$ & 0.140 \\
\hline
\end{tabular}

Percentages are shown in parentheses. MV, Mitral valve; ePTFE, expanded polytetrafluoroethylene; SD, standard deviation; NYHA, New York Heart Association.

repair have been so satisfactory that surgery is often recommended for asymptomatic MR. ${ }^{9}$

The introduction of expanded polytetrafluoroethylene (ePTFE) sutures to replace chordae tendineae ${ }^{10}$ increased the probability of MV repair in patients with MR resulting from myxomatous disease of the MV., 11

This report is a study on the long-term results of MV repair for MR resulting from myxomatous disease of the MV. It also examines the late effects of chordal replacement with ePTFE sutures during MV repair.

\section{Patients and methods}

From 1981 to 1995 , 417 patients with MR resulting from myxomatous disease were operated on by one surgeon at The Toronto Hospital; 324 patients had MV repair and 93 had MVR. Chordal replacement with ePTFE was first used in July 1985. The proportion of valves repaired increased from $30 \%$ in 1985 to approximately $90 \%$ by 1990 and thereafter. This increase in the rate of valve repair was largely due to the use of chordal replacement with ePTFE sutures. ${ }^{4}$

Table I shows the clinical data of all patients who had MV repair, as well as of the subgroups who had repair with and without chordal replacement with ePTFE sutures. 
Operations were performed with the use of cardiopulmonary bypass and mild systemic hypothermia. During aortic crossclamping, myocardial protection was provided by intermittent cold crystalloid cardioplegia until 1984 and cold blood cardioplegia thereafter. Intraoperative Doppler echocardiography was routinely used after 1988. Prolapse of the leaflets was determined during the operation by carefully examining the level of the free margins of every segment of the leaflets and comparing each level to the level of a relatively normal one, for example, the lateral commissural area of the posterior leaflet. The degree of myxomatous changes in the leaflets was arbitrarily classified as mild if only the prolapsing segment (e.g., the central scallop of the posterior leaflet) was grossly involved by the myxomatous process, moderate if both leaflets displayed some myxomatous changes, and severe when both leaflets were myxomatous and contained multiple aneurysms.

Prolapse of the posterior leaflet was managed by rectangular or quadrangular resection, but not more than one third of the posterior leaflet was resected. If the prolapse involved more than one third of the posterior leaflet, it was corrected by chordal replacement with ePTFE sutures. Prolapse of the anterior leaflet was managed by chordal shortening, chordal transfer, or chordal replacement with ePTFE sutures. As we gained experience with chordal replacement with ePTFE sutures, the first two techniques were abandoned altogether.

The technique of chordal replacement with ePTFE (Fig. 1) did not change during the study interval. We used 5-0 PTFE sutures* for prolapse of the anterior leaflet and 6-0 for the posterior leaflet and commissural areas. A 5-0 suture was passed two or three times through the fibrous portion of the papillary muscle head and the ends were tied together. Each arm of the suture was then passed twice through the free margin of the leaflet, entering it through the area where the native chorda was attached. The two arms of the suture were no more than 4 or $5 \mathrm{~mm}$ apart at the free margin of the leaflet. The length of the ePTFE chordae was determined by comparison with the opposing leaflet or by distending the left ventricle with saline solution and observing where the free margins of the leaflets should coapt. Once this was done, the two ends were passed through the leaflet into its ventricular surface and tied together. The number of new chordae ranged from 2 to 16 , mean of 6.6 per patient, assuming that each PTFE suture corresponded to two new chordae.

Most patients also had a ring annuloplasty. Rigid and flexible rings were used until 1991; since then only flexible rings have been used. Patients with prosthetic mitral rings were given warfarin sodium for anticoagulation during the first 3 months if they were in sinus rhythm and permanently if atrial fibrillation persisted. Table II summarizes the operative procedures performed.

Patients were followed up by their referring cardiologists and our valve registry personnel. Postoperative events were compiled and analyzed according to the "Guidelines for Reporting Morbidity and Mortality After Cardiac Valvular Operations." 12

* Gore-Tex suture, registered trade mark of W. L. Gore \& Associates, Inc., Flagstaff, Ariz.

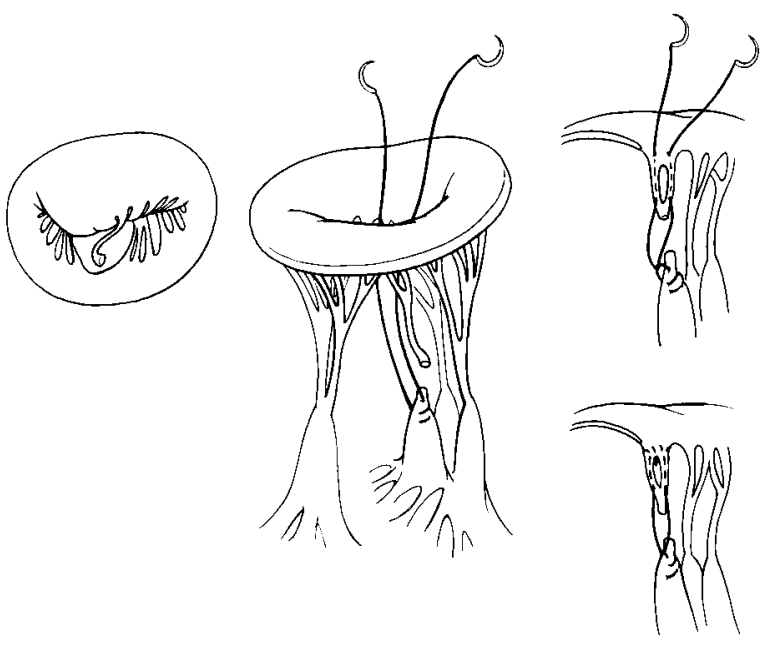

Fig. 1. Technique of chordal replacement with ePTFE suture.

Statistical analysis. Statistical analysis was performed with the BMDP 1L program (BMDP Statistical Software, Berkeley, Calif.). Discrete data were analyzed by $\chi^{2}$ or Fisher's exact test where appropriate. Longitudinal data were analyzed univariately by the productlimit or Kaplan-Meier estimate. For these analyses, time zero was normalized for all patients to the date of operation, and the time to an event such as death, thromboembolism, reoperation, or recurrent MR was calculated as the event date minus the date of operation. Patients who did not have an event were censored at the time of the last follow-up. Results of these longitudinal data were expressed in percentages of the means and the percentages of the standard errors of the means. Clinical, hemodynamic, or operative variables that were different by univariate analysis at $p<0.25$ were entered into a Cox proportional hazard model to determine the multivariate, independent predictors of an event.

\section{Results}

There were two operative deaths. One young man who had MV repair and aortic valve replacement with a freehand aortic homograft had a cardiac arrest 10 hours after the operation and could not be resuscitated. Autopsy showed dehiscence of the muscle bar of the homograft and acute left ventricular outflow tract obstruction. An elderly man died suddenly 1 week after the operation. Autopsy revealed an acute type A aortic dissection with rupture in the pericardial sac. Both patients had had chordal replacement with ePTFE suture.

Ten patients had intraoperative complications: Nine patients required a second pump run to correct residual moderate MR (five as a result of systolic anterior motion of the anterior leaflet), and one 


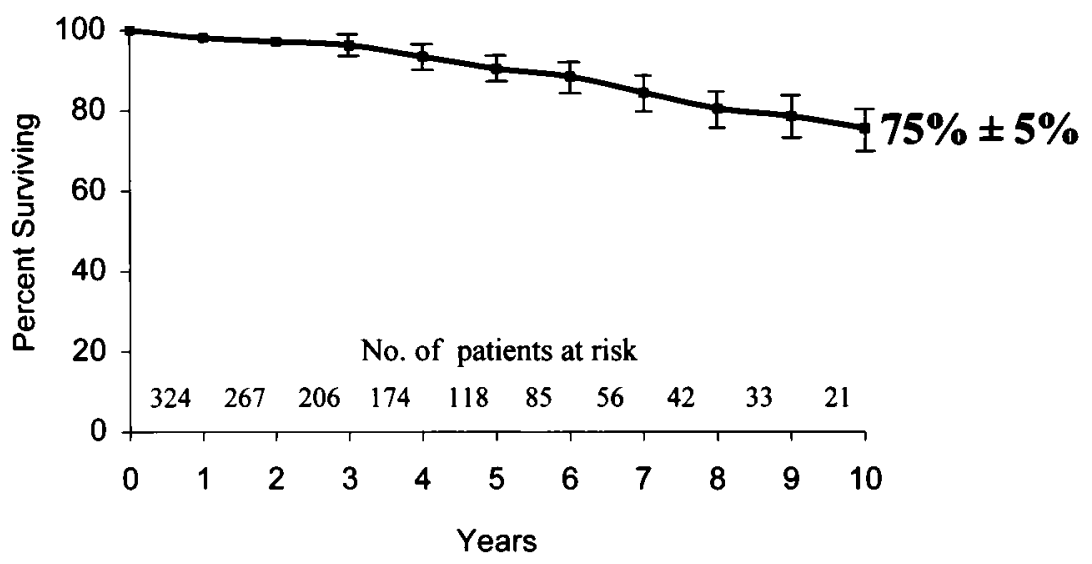

Fig. 2. Actuarial survival after MV repair.

Table II. List of operations performed

\begin{tabular}{|c|c|c|c|}
\hline & All patients & ePTFE & No ePTFE \\
\hline \multicolumn{4}{|l|}{ MV repair } \\
\hline Partial resection of posterior leaflet & $260(80)$ & $116(68)$ & $150(94)$ \\
\hline Chordal replacement with ePTFE & $165(60)$ & $165(100)$ & 0 \\
\hline Chordal shortening & $63(19)$ & $44(27)$ & $19(12)$ \\
\hline Chordal transfer & $12(4)$ & $2(1)$ & $10(6)$ \\
\hline Ring annuloplasty & $279(86)$ & $142(86)$ & $137(86)$ \\
\hline \multicolumn{4}{|l|}{ Aortic valve surgery } \\
\hline Repair & $10(3)$ & $8(5)$ & $2(1)$ \\
\hline Replacement & $11(4)$ & $9(5)$ & $2(1)$ \\
\hline Replacement of ascending aorta & $7(2)$ & $5(3)$ & $2(1)$ \\
\hline Tricuspid valve repair & $9(3)$ & $6(4)$ & $3(2)$ \\
\hline Coronary artery bypass & $40(16)$ & $16(10)$ & $24(15)$ \\
\hline Maze procedure for atrial fibrillation & $7(6)$ & $5(3)$ & $2(1)$ \\
\hline
\end{tabular}

Percentages are shown in parentheses. ePTFE, Expanded polytetrafluoroethylene; $M V$, mitral valve.

patient had an acute type A aortic dissection and required replacement of the ascending aorta.

Thirty-nine patients had one or more postoperative complications: reexploration of the mediastinum for hemorrhage in 19, myocardial infarction in 1 , implantation of a permanent transvenous pacemaker in 20 , ischemic stroke in 1 , hemorrhagic stroke in 1, transient cerebral ischemic attacks in 3, and severe hemolysis necessitating MVR in 1.

Patients were followed up from 6 to 156 months, mean of $36 \pm 30$ months (mean \pm standard deviation). Twenty-one late deaths occurred: 14 cardiac and 7 noncardiac. Of the cardiac deaths, 6 were due to congestive heart failure, 4 were due to thromboembolic complications, 1 was due to anticoagulation-related hemorrhage, 2 were due to myocardial infarction, and 1 was a sudden death. A Cox regression analysis identified age greater than 60 years as the only independent variable associated with an increased risk of late death. The actuarial survival was $77 \% \pm 5 \%$ at 10 years (Fig. 2).

After the third postoperative month, 72 patients continued to receive warfarin because of persistent atrial fibrillation, 140 were started on a regimen of aspirin by their referring cardiologist, and 88 received no anticoagulants or antiplatelet agents. Including the perioperative events, thromboembolic complications occurred in 25 patients: 11 had transient ischemic attacks and 14 had strokes. Four patients died of the stroke, four had various degrees of permanent neurologic deficit, and six recovered completely. Twelve of the 14 strokes occurred during the first postoperative year. Transient ischemic attacks occurred at random. Atrial fibrillation, the presence of an annuloplasty ring, the degree of myxomatous changes in the MV leaflets, and the presence of ePTFE chordae had no effect on the risk of thromboembolism. Actually, no variable could be 


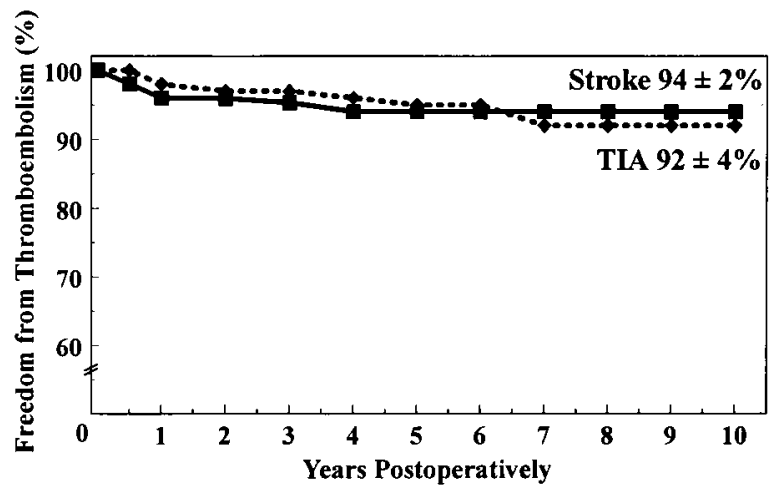

Fig. 3. Freedom from thromboembolic complications.

identified as predictive of this complication. The freedom from thromboembolic complications is shown in Fig. 3. Two hemorrhagic complications occurred in the same patient: cerebral bleeding 1 week after the operation and gastrointestinal bleeding, which caused the patient's death, 36 months after the operation.

Infective endocarditis developed in only one patient, 13 months after aortic valve and MV repair, and necessitated double valve replacement. The freedom from infective endocarditis was $99 \% \pm$ $0.5 \%$ at 10 years.

Reoperations on the MV were necessary in 10 patients. The indication for a second operation was recurrent MR in eight patients and hemolysis in two. A second MV repair was performed in four and MVR in six patients. No operative deaths occurred among these 10 patients. Eight of the 10 reoperations were performed during the first postoperative year. Six of these 10 patients had had chordal replacement with ePTFE sutures. A Cox regression analysis identified advanced myxomatous changes in the MV leaflets as the only factor associated with increased risk of reoperation. Fig. 4 shows the freedom from MV reoperation in all patients. For the subgroup of patients who had chordal replacement with ePTFE, the freedom from reoperation was $94 \% \pm 2 \%$, and for those without chordal replacement it was $97 \% \pm 1 \%$.

In addition to 10 patients who required a second MV operation, two others required coronary artery bypass grafting, but nothing was done to their normally functioning MV.

At the time of the most recent follow-up contact, 295 patients were alive and had their native MV; 195 $(66 \%)$ were in New York Heart Association functional class I, $78(26 \%)$ were in class II, and $22(7 \%)$ in class III.

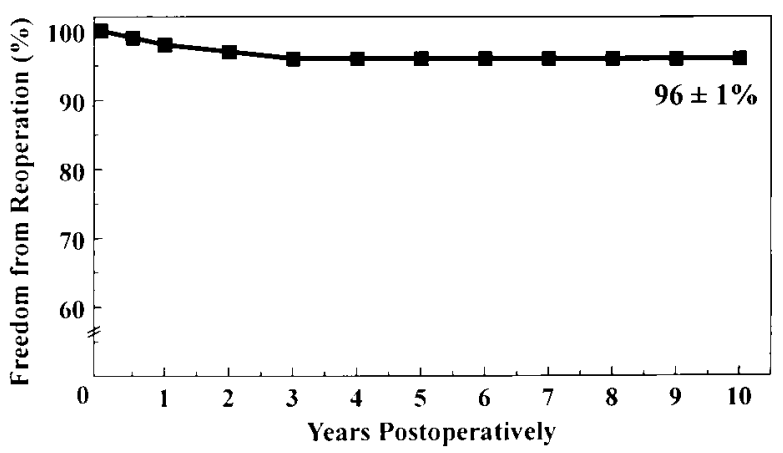

Fig. 4. Freedom from MV reoperation.

The most recent Doppler echocardiographic study revealed mild or no MR in $269(91 \%)$ patients, moderate MR in 25 (8.4\%), and severe MR in 2. These two patients with severe MR were being managed medically because of advanced age in one (age 90 years) and complex disease in the other (the patient in whom acute type A aortic dissection developed during the operation). The freedom from recurrent severe MR was $93 \% \pm 2 \%$ at 10 years.

The most recent electrocardiogram showed sinus rhythm in 223 patients, atrial fibrillation in 64, and paced beats in 8 .

\section{Discussion}

MR in patients with myxomatous disease of the $\mathrm{MV}$ is often due to prolapse of the middle scallop of the posterior leaflet. ${ }^{13}$ Isolated prolapse of the posterior leaflet was found in $52 \%$ of our patients. Repair of prolapse of the middle scallop is relatively simple and usually can be accomplished by resection of the prolapsing segment. ${ }^{14} \mathrm{We}^{15}$ have observed that resections larger than $1.5 \mathrm{~cm}$ with plication in a single point impairs contractility of the posterior wall of the left ventricle. When more than $1.5 \mathrm{~cm}$ of posterior leaflet is resected, twice as much remaining posterior leaflet should be detached from the anulus and the sliding leaflet technique of Carpentier used, ${ }^{16}$ because it prevents the problem of posterior wall motion abnormality. In addition, plication of a large segment of the mitral anulus in patients with a dominant circumflex artery may cause kinking or obstruction of that artery with consequent myocardial ischemia. ${ }^{17}$

Prolapse of the middle scallop of the posterior leaflet increases the stresses in the central area of the anterior leaflet. ${ }^{18,19} \mathrm{We}$ believe that longstanding prolapse of the middle scallop of the posterior leaflet may cause prolapse of the central portion of 
the anterior leaflet. This is probably the mechanism of bileaflet prolapse in patients with mild myxomatous changes of the valve. Bileaflet prolapse was present in $30 \%$ of our patients. The remaining $18 \%$ of our patients had isolated prolapse of the anterior leaflet, which was due to elongation or rupture of chordae tendineae. Chordal replacement with ePTFE sutures has allowed us to repair the MV in approximately $90 \%$ of the patients with anterior or bileaflet prolapse. Other surgeons have reported similar proportions of MV repair without the use of ePTFE sutures. ${ }^{14,17}$ Two techniques frequently used to correct prolapse of the anterior leaflet are chordal shortening for an elongated chorda ${ }^{14}$ and chordal transfer for an elongated or ruptured chorda. ${ }^{17}$ Chordal shortening has been reported to be associated with a higher failure rate than chordal transfer. ${ }^{20}$ Smedira and associates ${ }^{20}$ reported a 5 -year freedom from reoperation of $96 \%$ after chordal transfer and of $74 \%$ after chordal shortening. Salati and colleagues ${ }^{17}$ reported on the midterm results of chordal transfer to correct MR caused by prolapse of the anterior leaflet, and the freedom from reoperation was $88 \%$ at 5 years. The freedom from recurrent severe MR was $93 \%$ at 10 years in our patients. Although other factors may have prevented recurrent MR in our patients, we believe that the liberal use of multiple ePTFE sutures to replace elongated and ruptured chordae tendineae and also to reinforce flimsy chordae played an important role in this successful late outcome. None of our failures was due to the ePTFE chordae, but they may have caused elongation of adjacent native chordae because of increased stress if the ePTFE chordae were not the same length as the native chordae. ${ }^{18,19}$

The ePTFE chordae become completely covered by a fibrous sheath after the first year of implantation in human beings. ${ }^{10,21}$ Examination of explanted ePTFE chordae reveals that they remain pliable and the fibrous sheath is covered by a single layer of endothelial cells. ${ }^{21}$

The surgical pathology of myxomatous mitral leaflets varies widely from minimal interchordal hooding and increased leaflet area to extremely voluminous leaflets that contain large aneurysms. The leaflets are often opaque and thickened, but not always in a uniform fashion; the lateral half of the MV may appear entirely normal while the medial half is grossly abnormal. We have observed that the medial half of the MV frequently has more advanced myxomatous changes than its lateral half. The chordae tendineae can be thin and elongated, but sometimes thickened or even fused and calcified. The mitral anulus is always dilated in patients with myxomatous disease of the MV. The posterior mitral anulus may become segmentally or entirely calcified. This calcification may extend into the posterior wall of the left ventricle, making removal of that segment of the leaflet hazardous. MV repair is usually feasible in patients with advanced myxomatous disease and even with calcification of the mitral anulus, ${ }^{22,23}$ but the probability of failure of the repair is higher in these patients than in those with more localized disease. Although the long-term results of MV repair are better than those of MVR, we have found that MVR with preservation of chordae tendineae gives very satisfactory long-term results in these patients. ${ }^{24}$ However, it is associated with higher rates of valve-related complications.

In conclusion, MV repair is feasible in most patients with MR resulting from myxomatous disease and is associated with a relatively low rate of valve-related complications. Chordal replacement with ePTFE sutures is a durable operative procedure and it does not increase the risk of valverelated complications. Patients with advanced myxomatous changes in both leaflets have an increased risk of reoperation because of MV failure.

\section{REFERENCES}

1. Levy D, Savage D. Prevalence and clinical features of mitral valve prolapse. Am Heart J 1987;113:1281-90.

2. Nishimura RA, McGoon MD, Shub C, et al. Echocardiographically documented mitral valve prolapse: long-term follow-up of 237 patients. N Engl J Med 1985;313:1305-9.

3. Olson LJ, Subramanian R, Ackermann DM, Orszulak TA, Edwards WD. Surgical pathology of the mitral valve: a study of 712 cases spanning over 21 years. Mayo Clin Proc 1987; 62:22-34.

4. David TE, Armstrong S, Sun Z, Daniel L. Late results of mitral valve repair for mitral regurgitation due to degenerative disease. Ann Thorac Surg 1993;56:7-14.

5. Cohn LH, Couper GS, Aranki SF, Rizzo RJ, Kinchla NM, Collins JJ Jr. Long-term results of mitral valve reconstruction for regurgitation of the myxomatous mitral valve. J Thorac Cardiovasc Surg 1994;107:143-50.

6. Deloche A, Jebara VA, Relland JYM, et al. Valve repair with Carpentier techniques: the second decade. J Thorac Cardiovasc Surg 1990;99:990-1002.

7. David TE, Uden DE, Strauss HD. The importance of the mitral apparatus in left ventricular function after correction of mitral regurgitation. Circulation 1983;68(Suppl):II76-82.

8. Yacoub M, Halim M, Radley-Smith R, et al. Surgical treatment of mitral regurgitation caused by floppy valves: repair versus replacement. Circulation 1981;64(Suppl):II211-6.

9. Ling LH, Enriques-Sarano M, Seward JB, et al. Clinical outcome of mitral regurgitation due to flail leaflet. $\mathrm{N}$ Engl J Med 1996;335:1417-23.

10. Vetter HO, Burack JH, Factor SM, Macaluso F, Frater 
RWM. Replacement of chordae tendineae of the mitral valve using the new expanded PTFE suture in sheep. In: Bodnar E, Yacoub M, editors. Biologic bioprosthetic valves. New York: Yorke Medical Books; 1986. p. 772-84.

11. David TE, Bos J, Rakowski H. Mitral valve repair by replacement of chordae tendineae with polytetrafluoroethylene sutures. J Thorac Cardiovasc Surg 1991;101:495-501.

12. Edmunds LH, Clark RE, Cohn LH, Grunkemeier GL, Miller DC, Weisel RD. Guidelines for reporting morbidity and mortality after cardiac valvular operations. Ann Thorac Surg 1996;62:932-5

13. Ranganathan N, Lam JHC, Wigle ED, Silver MD. Morphology of the human mitral valve. II. The valve leaflets. Circulation 1970;41:459-66.

14. Carpentier A. Cardiac valve surgery: the "French correction." J Thorac Cardiovasc Surg 1983;86:323-37.

15. David TE, Komeda M, Pollick C, Burns RJ. Mitral valve annuloplasty: the effect in left ventricular function after correction of mitral regurgitation. Ann Thorac Surg 1989;47: 524-8.

16. Jebara VA, Mihaileanu S, Acar C, et al. Left ventricular outflow tract obstruction after mitral valve repair: results of the sliding leaflet technique. Circulation 1993;88(Suppl): II30-4.

17. Salati M, Moriggia S, Scrofani R, Santoli C. Chordal transposition for anterior mitral prolapse: early and long-term results. Eur J Cardiothorac Surg 1997;11:268-73.

18. Kunzelman KS, Cochran RP, Chuong C, et al. Finite element analysis of the mitral valve. J Heart Valve Dis 1993;2:326-40.

19. Reimink MS, Kunzelman KS, Cochran RP. The effect of chordal replacement suture length on function and stresses in repaired mitral valves: a finite element analysis. J Heart Valve Dis 1996;5:365-75.

20. Smedira NG, Selman R, Cosgrove DM, et al. Repair of anterior leaflet prolapse: chordal transfer is superior to chordal shortening. J Thorac Cardiovasc Surg 1996;112:28792.

21. Zussa C, editor. Artificial chordae in mitral valve surgery. Austin [TX]: RG Landes Company; 1994. p. 75-112.

22. David TE, Feindel CM, Armstrong S, Sun Z. Reconstruction of the mitral anulus: a ten-year experience. J Thorac Cardiovasc Surg 1995;110:132-42.

23. Carpentier AF, Pellerin M, Fuzellier JF, Relland JYM. Extensive calcification of the mitral valve anulus: pathology and surgical management. J Thorac Cardiovasc Surg 1996; 111:718-30.

24. David TE. Left ventricular function after mitral valve surgery. J Heart Valve Dis 1995;4(Suppl):II175-80.

\section{Discussion}

Dr. Lawrence H. Cohn (Boston, Mass.). This presentation validates for me that MV repair with ePTFE, particularly with anterior leaflet and chordal replacement, is the technique of choice. I think this is a much more reproducible technique, it is much less traumatic, and it is much easier to do. Reproducibility and simplicity are of primary importance in MV repair. Dr. David, you are to be congratulated for validating this in this excellent series.

We began using this technique routinely about 3 years ago. We have a much smaller series, about 40 patients whom we have followed up over a period of time, and none of these patients has had any recurrence of MR or any incidence of structural valve degeneration. Although ours is a much smaller series, I think it helps to validate your point.

I have a few questions related to your data and this technique. First, you mentioned that you use annuloplasty rings in $75 \%$ of the patients. Was the incidence of recurrent MR, either acutely or chronically, higher in the $25 \%$ of patients that did not get an annuloplasty ring?

You also pointed out also that your incidence of heart block was almost $6 \%$ in MV repair. That is a little bit higher than I have seen, and I wondered if you could discuss the reason for this higher incidence.

You also used ePTFE chordae for posterior leaflet repair in a number of patients. In what circumstances might you use a PTFE chorda for posterior leaflet repair when usually resection is all that would be needed?

I congratulate you on describing to us the difficult part of adjusting the length of the ePTFE chordae. In my experience as well, making them too short is the trickiest part of this technique.

Dr. David. Thank you, Dr. Cohn. I am glad that I convinced you to start using ePTFE as well.

We compared patients with and without annuloplasty rings by univariate and multivariate analysis as a predictor for failure of MV repair, and it was not a predictor. However, that when we resect the posterior leaflet, we do reinforce the anulus with a pledget-supported suture when plicating a single area. We do less and less plication of a single area since I learned, with Dr. Carpentier, about his sliding plasty. I believe that it not only decreased the risk of systolic anterior motion, but also improved systolic function in the operating room. Extensive plication in a single area invariably is followed by an akinetic segment in the posterior wall. Carpentier's sliding plasty prevents that.

I agree that the incidence of heart block in this series is a bit higher than reported before, at $5.4 \%$, but I do not know the reason. Perhaps the sutures holding the ring in the medial fibrous trigone may have penetrated the bundle. Interesting, one half of all patients who had a pacemaker were in sinus rhythm when they came back for the first follow-up visit 2 months postoperatively, indicating that we were overly aggressive in implanting pacemakers, mostly because of pressure to discharge patients prematurely. This is particularly true after the maze procedure. These patients frequently do not have an intact sinus mechanism and they might require atrial pacing for a week or 10 days. The pressure to discharge them after 4 or 5 days is so great that we may have to start sending them home with a temporary pacer and check on them daily by telephone.

The cases of posterior leaflet repair that necessitated PTFE are those in which just about the entire posterior leaflet was flail. I normally resect the midportion of the scallop. I am reluctant to resect the commissural area unless the patient had endocarditis at that site, in which case I do a sliding plasty. Most of the posterior leaflets that had PTFE chorda had it placed mostly in the commissural areas.

Dr. Norberto G. De Vega (Malaga, Spain). I want to comment about the use of rings. We very seldom use a ring when we repair degenerative MVs. Using a ring is like paying a tax for doing a mitral repair. And I continue to 
encounter surgeons who do not use rings, Professor Yacoub, for one. It was very nice to hear from you that you do not always use rings and that the long-term result of your operations is not related to the use of rings.

My question was whether there was any difference in the long-term result, and you have already said no. My message is that probably too many rings are used in MV repairs.

Dr. David. I do not know what happens first, the annular dilatation or the chordal elongation. Patients who have advanced myxomatous disease may have a dilated fibrous skeleton, that is, the anulus dilates and, as it dilates, it increases the wall tension on the leaflets and the leaflets begin to stretch.

I used an annuloplasty ring in all my patients with obvious myxomatous change in the leaflets. Those who did not have a ring largely had what Professor Carpentier refers to as fibroelastic deficiency. My pathologists claim that there is no pathologic substrate for this disease. We all know what fibroelastic deficiency is: If the leaflet is thin, flimsy, extremely attenuated, we call this fibroelastic deficiency. Those patients frequently have a normal mitral anulus. I agree with you that those patients do not need an annuloplasty ring.

\section{ON THE MOVE?}

Don't miss a single issue of the journal! To ensure prompt service when you change your address, please photocopy and complete the form below.

Please send your change of address notification at least six weeks before your move to ensure continued service. We regret we cannot guarantee replacement of issues missed due to late notification.

\section{JOURNAL TITLE:}

Fill in the title of the journal here.

\section{OLD ADDRESS:}

Affix the address label from a recent issue of the journal here.

\section{NEW ADDRESS:}

Clearly print your new address here.

Name

Address

City/State/ZIP
COPY AND MAIL THIS FORM TO:

Periodical Subscription Services

Mosby, Inc.

11830 Westline Industrial Dr.

St. Louis, MO 63146-3318
OR FAX TO:

314-432-1158

N/ Mosby
OR PHONE:

1-800-453-4351

Outside the U.S., call

314-453-4351 